\title{
Assistência de enfermagem à criança com câncer em cuidados paliativos: uma revisão integrativa
}

\author{
Nursing care for children with cancer in palliative care: an integrative review \\ Atención de enfermería para niños con cáncer en cuidados paliativos: una revisión integrativa \\ Taison Regis Penariol Natarelli ${ }^{1}$ (D) https://orcid.org/0000-0002-4578-8626 \\ Gabriela Marchiori Carmo Azzolin ${ }^{1}$ (D) https://orcid.org/0000-0003-1888-7597 \\ Viviana Aparecida de Lima ${ }^{1}$ (D) https://orcid.org/0000-0001-9609-3798
}

\section{Resumo}

Este estudo objetivou compreender a importância dos cuidados paliativos à criança com doença oncológica, bem como identificar e analisar as intervenções de enfermagem nesse âmbito do cuidado. Foi realizada uma revisão integrativa da literatura utilizando as bases de dados e bibliotecas virtuais: SciELO, LILACS e PubMed. A coleta de dados ocorreu no período de março a junho de 2019. Foram encontrados 17 artigos científicos, os quais foram analisados, catalogados e discutidos conforme as unidades temáticas extraídas de sua leitura. Concluise que os cuidados paliativos contribuem para o aumento da qualidade de vida da criança e de sua família. 0 enfermeiro participa de todas as etapas dos cuidados paliativos, desde a sua introdução precoce no tratamento, na construção de vínculo, apoio à criança, à família e à equipe, alívio e controle da dor, até o momento da morte da criança e no período de luto da família.

\section{Abstract}

This study aims to understand the importance of the palliative care for children with oncological disease, as well as identify and analyze the nursing interventions in this area of health care. An integrative review of the literature was undertaken using the databases: SciELO, LILACS and PubMed. The data collect was made from March to June of 2019. Seventeen scientific articles were found, they were analyzed, cataloged and discussed from the thematic units taken from their reading. It is concluded that the palliative care contributes to increase the quality of life of children and their families. The nurse is involved in all phases of the palliative care, since its early integration in the treatment, in building the bonding, in support to the child, family and nursing team, pain relief and management, until the moment of the child's death and during the family mourning.

\section{Resumen}

El objetivo de este estudio es comprender la importancia de los cuidados paliativos para los niños con enfermedades oncológicas, así como identificar y analizar las intervenciones de enfermería en esta área de la atención médica. Se realizó una revisión integrativa de la literatura utilizándose las bases de datos: SciELO, LILACS y PubMed. La recolección de datos se realizó de marzo a junio de 2019. Fueron encontrados 17 artículos científicos, analizados, catalogados y discutidos a partir de las unidades temáticas tomadas de sus lecturas. Se concluye que los cuidados paliativos contribuyen para aumentar la calidad de vida de los niños y sus familias. El enfermero participa de todas las fases de los cuidados paliativos, desde su integración temprana en el tratamiento, en la construcción de lazos, en el apoyo al niño, a la familia y al equipo de enfermería, alivio y manejo del dolor, hasta el momento de la muerte del niño y durante el duelo familiar.

\section{Como citar:}

Natarelli TR, Azzolin GM, Lima VA. Assistência de enfermagem à criança com câncer em cuidados paliativos: uma revisão integrativa. Rev Soc Bras Enferm Ped. 2020;20(2):97-107.

${ }_{1}^{1}$ Pontifícia Universidade Católica de Campinas, Campinas, SP, Brasil

Conflitos de interesse: nada a declarar.

Submetido: 26 de Agosto de 2019 | Aceito: 26 de Março de 2021

Autor correspondente: Taison Regis Penariol Natarelli | E-mail: taison.natarelli@hotmail.com

DOI: http://dx.doi.org/10.31508/1676-3793202000014 


\section{Introdução}

O processo de trabalho em enfermagem caracteriza-se como vivo e dinâmico, envolvendo atividades das esferas do cuidado, da administração, da pesquisa e da educação, com destaque para o papel do enfermeiro como líder da equipe de enfermagem e responsável pela articulação entre os membros da equipe multiprofissional. Atualmente é cada vez mais exigido dos serviços de saúde um modelo de assistência humanizado que valorize o diálogo entre os profissionais e a participação do paciente na construção de um plano terapêutico individualizado, e especialmente na área da pediatria é preconizado que a unidade adote um modelo de cuidado centrado na família, propiciando, dessa forma, um cuidado integral e acolhedor..$^{(1)}$

A humanização e a integralidade do cuidado se fazem essenciais, principalmente ao lidar com doenças que ameaçam a vida, como as oncológicas, quando se pensa nas repercussões emocionais para o paciente e a sua família. Câncer infantil é o nome dado a um conjunto de doenças que apresentam proliferação descontrolada de células anormais e geralmente é de natureza embrionária e constituído de células indiferenciadas, afetando, na maioria dos casos, as células do sistema sanguíneo e os tecidos de sustentação. Os tipos de neoplasias mais frequentes na infância são: leucemias (glóbulos brancos), tumores do sistema nervoso central e linfomas (sistema linfático). ${ }^{(2)}$ De acordo com os dados do Instituto Nacional de Câncer (INCA), no Brasil o câncer infantil apresenta prevalência de aproximadamente $3 \%$, sendo considerado uma das cinco principais causas de óbito na infância. ${ }^{(3)}$ Contudo, por meio de políticas públicas e implantações de centros especializados, a taxa de cura ultrapassa hoje cerca de $70 \%$ dos casos. ${ }^{(4)}$

O enfermeiro é protagonista no cuidado da criança com câncer em todas as suas fases, participando na prevenção, diagnóstico precoce, tratamento e cuidados paliativos. Dentre essas fases, destaca-se o cuidado paliativo, uma abordagem que visa ao aumento da qualidade de vida do paciente e da família, que estão enfrentando uma doença que ameaça a vida. Esse tipo de assistência visa prevenir e amenizar o sofrimento, seja ele de ordem física, psíquica, social ou espiritual, bem como promover dignidade e adaptação à progressão da doença. Suas práticas são basea- das em evidências e envolvem o diagnóstico precoce, avaliação adequada e tratamento da dor e de demais problemas. $\mathrm{O}$ acesso aos cuidados paliativos deve ser universal, considerando as especificidades e vulnerabilidades de grupos marginalizados e populações de baixa renda. O cuidado paliativo em pediatria abrange o cuidado integral à criança nas dimensões biopsicossociais, em todas as fases do desenvolvimento - do neonato ao jovem adulto -, além de fornecer suporte à família, incluindo irmãos e parentes, além do núcleo familiar. Inicia-se desde o momento do diagnóstico e permeia todo o processo de assistência à criança, esteja ela recebendo tratamento direto para a doença ou não. A população infantil possui uma gama maior de condições que requerem cuidados paliativos, quando comparadas aos adultos, tendo em vista as condições específicas e exclusivas da infância, como, por exemplo, fatores neonatais, anomalias genéticas, condições congênitas, distúrbios neurológicos e doenças raras. ${ }^{(5)}$

O enfermeiro, com a equipe multiprofissional, objetiva auxiliar a família e a criança no processo de enfrentamento da doença com respeito e dignidade. Entretanto, o profissional de enfermagem que lida com a assistência direta à criança com câncer apresenta sentimentos de tristeza e sofrimento relacionados com a sua própria rotina de trabalho e, ainda que busque recursos como a separação entre vida pessoal e profissional caracterizada pelo distanciamento, revela-se a falta de preparo emocional para lidar com tais questões referentes ao processo de morrer e a necessidade de amparo psicológico à equipe de cuidadores. ${ }^{(6)}$

A morte é uma temática que surge inevitavelmente na área da oncologia pediátrica, cabendo muitas vezes ao enfermeiro, profissional que passa a maior parte do tempo junto ao paciente, lidar com essa questão. As possibilidades de atuação do enfermeiro nesse momento podem ser divididas em dois grupos: as objetivas (promoção de conforto e alívio da dor por meio de métodos farmacológicos e não farmacológicos, entre outras técnicas) e as subjetivas (cuidar da família por meio da construção de um vínculo de confiança e afeto, promover o controle da ansiedade e depressão). Nesse contexto, o enfermeiro se depara com fatores que dificultam sua prática, como a falta de autonomia para tomar decisões, além da falta de formação específica e de compreensão a respeito do processo de morrer e como lidar com ele..$^{(6,7)}$ 
Esta pesquisa é importante por se aprofundar nas questões relativas aos cuidados paliativos na área da oncologia pediátrica, sobretudo quanto ao papel do enfermeiro como membro da equipe multiprofissional, produzindo conhecimento científico e sistematizado que embase a prática do enfermeiro que atua na assistência à criança com câncer e sua família, levando-o também à reflexão crítica dos aspectos éticos do cuidado em oncologia pediátrica, além de contribuir para o crescimento da produção científica brasileira a respeito dessa temática.

Este estudo apresentou como objetivos:

- Compreender e analisar a importância dos cuidados paliativos no tratamento da criança com câncer;

- Compreender e analisar o papel do enfermeiro como membro da equipe multiprofissional nos cuidados à criança com câncer e as possibilidades de intervenções de enfermagem voltadas ao paciente pediátrico no processo de morte e na morte.

\section{Métodos}

Foi realizada uma revisão integrativa da literatura com o objetivo de identificar estudos que possam agregar novos conhecimentos a respeito da temática proposta e levar a uma reflexão acerca do papel do enfermeiro nos cuidados paliativos à criança com doença oncológica.

Essa revisão obedeceu às seguintes etapas: identificação do tema e seleção da hipótese de pesquisa; estabelecimento de critérios de inclusão e exclusão de estudos; categorização dos estudos; avaliação dos estudos incluídos na pesquisa; interpretação dos resultados e apresentação da síntese do conhecimento. ${ }^{(8)}$

O levantamento bibliográfico ocorreu nas seguintes bases de dados e bibliotecas virtuais: Scientific Eletronic Library Online (SciELO), Literatura Latino-Americana e do Caribe em Ciências da Saúde (LILACS) e Biblioteca Nacional de Medicina dos Estados Unidos (PubMed). Para a busca, utilizaram-se os descritores indexados nos Descritores em Ciências da Saúde (DeCS): enfermagem pediátrica, oncologia e cuidados paliativos, e seus correlatos em espanhol e inglês. Foram realizadas as seguintes combinações entre os descritores: enfermagem pediátrica/oncologia/cuidados paliativos; enfermagem pediátrica/oncologia; enfermagem pediátrica/cuidados paliativos e oncologia/cuidados paliativos.
A coleta de dados ocorreu entre os meses de março e junho de 2019, e a seleção dos artigos obedeceu aos seguintes critérios de inclusão: artigos científicos disponíveis na íntegra em suas respectivas bases de dados, publicados no período entre 2011 e 2018, apresentados nos idiomas português, espanhol ou inglês. Foram excluídos outros tipos de estudos (monografias e teses).

Os artigos encontrados foram avaliados de acordo com os critérios de inclusão e exclusão preestabelecidos. Após essa primeira seleção, os artigos pré-selecionados foram analisados mediante título e resumo, com o intuito de verificar se os estudos apresentavam temática referente aos cuidados paliativos em oncologia pediátrica (Figura 1).

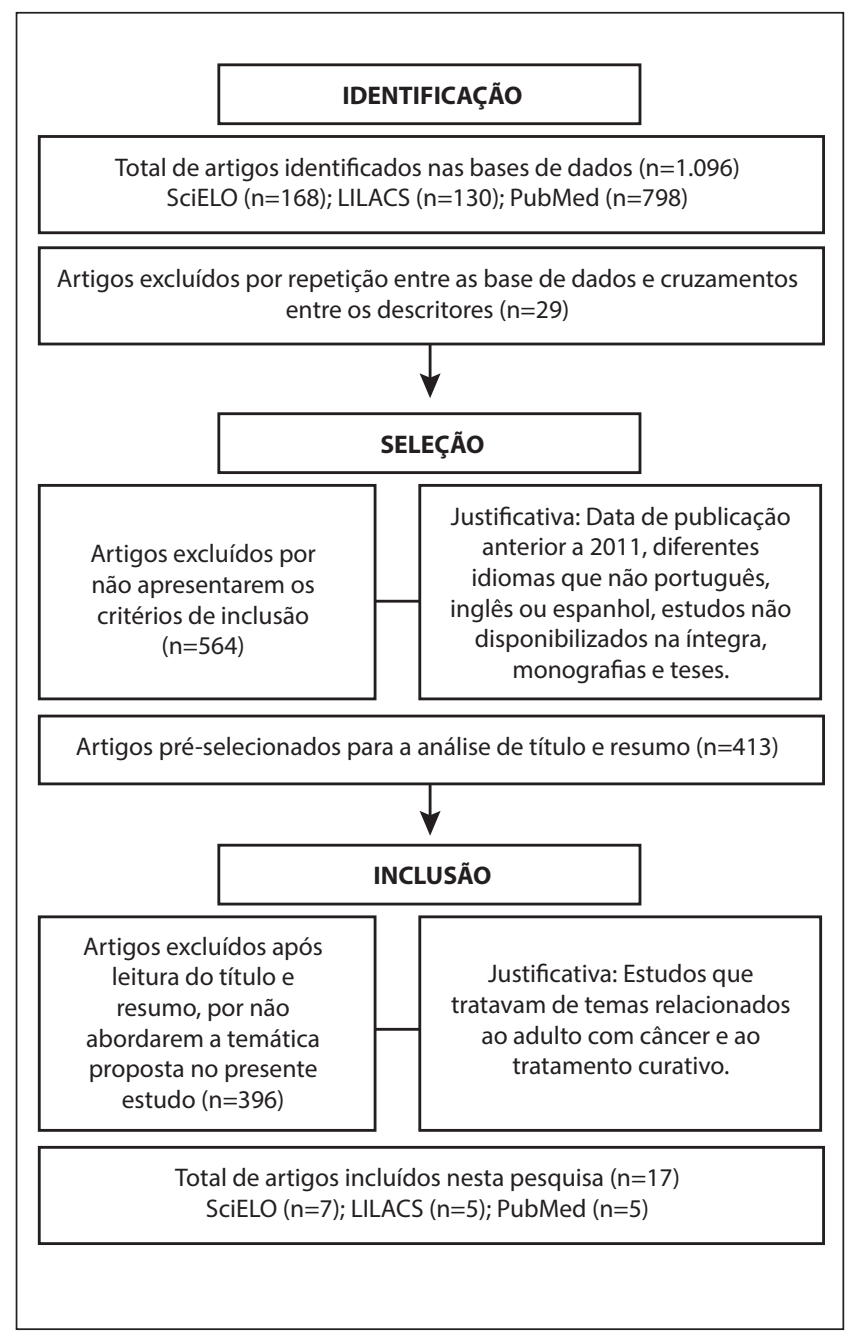

Figura 1. Anagrama da seleção dos artigos revisados

Após a seleção dos artigos, eles foram analisados, discutidos e catalogados. Para realizar a análise dos 
trabalhos, foi elaborada uma ficha de coleta de informações contendo especificações relativas à identificação do artigo e à temática abordada por ele. Posteriormente, as unidades temáticas mais relevantes foram extraídas por meio da análise dos artigos e pautaram a discussão.

\section{Resultados}

Após leitura e análise minuciosas dos artigos científicos selecionados, os estudos foram catalogados segundo a base de dados pesquisada, título do trabalho, periódico, ano, país/idioma e temática (Quadro 1).

Quadro 1. Apresentação dos artigos científicos da revisão integrativa da literatura

\begin{tabular}{|c|c|c|c|c|c|}
\hline $\begin{array}{l}\text { Base de } \\
\text { dados }\end{array}$ & Título & Periódico & Ano & País/Idioma & Temática \\
\hline LILACS & $\begin{array}{l}\text { A família da criança oncológica em } \\
\text { cuidados paliativos: } 0 \text { olhar da equipe de } \\
\text { enfermagem }\end{array}$ & $\begin{array}{l}\text { Ciência, Cuidado e } \\
\text { Saúde }\end{array}$ & 2011 & $\begin{array}{l}\text { Brasil/ } \\
\text { Português }\end{array}$ & $\begin{array}{l}\text { As experiências e as percepções da equipe de } \\
\text { enfermagem em relação à família da criança em } \\
\text { cuidados paliativos }\end{array}$ \\
\hline LILACS & $\begin{array}{l}\text { Enfoque interdisciplinar a la calidad de } \\
\text { vida y de muerte en oncopediatría }\end{array}$ & $\begin{array}{l}\text { Revista Cubana de } \\
\text { Enfermagem }\end{array}$ & 2011 & $\begin{array}{l}\text { Cuba/ } \\
\text { Espanhol }\end{array}$ & $\begin{array}{l}0 \text { manejo terapêutico adequado no processo viver/ } \\
\text { morrer em crianças e adolescentes com câncer }\end{array}$ \\
\hline LILACS & Cuidados paliativos à criança com câncer & $\begin{array}{l}\text { Revista de Enfermagem } \\
\text { da UERJ }\end{array}$ & 2013 & $\begin{array}{l}\text { Brasil/ } \\
\text { Português }\end{array}$ & $\begin{array}{l}\text { A experiência assistencial de enfermeiros no } \\
\text { cuidar de crianças com câncer sem possibilidades } \\
\text { terapêuticas }\end{array}$ \\
\hline LILACS & $\begin{array}{l}\text { Importância da comunicação nos } \\
\text { cuidados paliativos em oncologia } \\
\text { pediátrica: enfoque na Teoria Humanística } \\
\text { de Enfermagem (THE) }\end{array}$ & $\begin{array}{l}\text { Revista Latino- } \\
\text { Americana de } \\
\text { Enfermagem }\end{array}$ & 2013 & $\begin{array}{l}\text { Brasil/ } \\
\text { Português }\end{array}$ & $\begin{array}{l}\text { A comunicação nos cuidados paliativos em oncologia } \\
\text { pediátrica, sob o ponto de vista de enfermeiros, com } \\
\text { base na THE }\end{array}$ \\
\hline SciELO & $\begin{array}{l}\text { Morte digna da criança: percepção de } \\
\text { enfermeiros de uma unidade de oncologia }\end{array}$ & $\begin{array}{l}\text { Revista da Escola de } \\
\text { Enfermagem da USP }\end{array}$ & 2013 & $\begin{array}{l}\text { Brasil/ } \\
\text { Português }\end{array}$ & $\begin{array}{l}0 \text { significado e as intervenções de enfermeiros que } \\
\text { atuam em oncologia pediátrica na promoção de } \\
\text { morte digna da criança }\end{array}$ \\
\hline PubMed & $\begin{array}{l}\text { Pediatric Oncology Providers Perceptions } \\
\text { of Barriers and Facilitators to Early } \\
\text { Integration of Pediatric Palliative Care }\end{array}$ & $\begin{array}{l}\text { Pediatric Blood \& } \\
\text { Cancer }\end{array}$ & 2013 & EUA/Inglês & $\begin{array}{l}\text { As barreiras e os facilitadores na integração precoce } \\
\text { de cuidados paliativos em pacientes pediátricos }\end{array}$ \\
\hline SciELO & $\begin{array}{l}\text { Palliative care in pediatric hematological } \\
\text { oncology patients: experience of a tertiary } \\
\text { hospital }\end{array}$ & $\begin{array}{l}\text { Revista Brasileira } \\
\text { de Hematologia e } \\
\text { Hemoterapia }\end{array}$ & 2014 & $\begin{array}{l}\text { Brasil/ } \\
\text { Inglês }\end{array}$ & $\begin{array}{l}\text { Os cuidados paliativos e a abordagem aos pacientes } \\
\text { hemato-oncológicos em uma enfermaria de pediatria }\end{array}$ \\
\hline SciELO & $\begin{array}{l}\text { Relações estabelecidas pelos profissionais } \\
\text { de enfermagem no cuidado às crianças } \\
\text { com doença oncológica avançada }\end{array}$ & Aquichán & 2014 & $\begin{array}{l}\text { Colômbia/ } \\
\text { Português }\end{array}$ & $\begin{array}{l}\text { As relações estabelecidas pelos profissionais } \\
\text { de enfermagem no cuidado às crianças com } \\
\text { doença oncológica avançada, sem possibilidades } \\
\text { terapêuticas }\end{array}$ \\
\hline LILACS & $\begin{array}{l}\text { Cuidados paliativos em oncologia } \\
\text { pediátrica: percepções, saberes e práticas } \\
\text { na perspectiva da equipe multiprofissional }\end{array}$ & $\begin{array}{l}\text { Revista Gaúcha de } \\
\text { Enfermagem }\end{array}$ & 2015 & $\begin{array}{l}\text { Brasil/ } \\
\text { Português }\end{array}$ & $\begin{array}{l}\text { As percepções, saberes e práticas da equipe } \\
\text { multiprofissional na atenção às crianças em } \\
\text { cuidados paliativos em unidade de oncologia } \\
\text { pediátrica }\end{array}$ \\
\hline PubMed & $\begin{array}{l}\text { Good death for children with cancer: a } \\
\text { qualitative study }\end{array}$ & $\begin{array}{l}\text { Japanese Journal of } \\
\text { Clinical Oncology }\end{array}$ & 2015 & $\begin{array}{l}\text { Japão/ } \\
\text { Inglês }\end{array}$ & $\begin{array}{l}\text { As características de uma boa morte para crianças } \\
\text { com câncer }\end{array}$ \\
\hline PubMed & $\begin{array}{l}\text { Palliative Care as a Standard } \\
\text { of Care in Pediatric Oncology }\end{array}$ & $\begin{array}{l}\text { Pediatric Blood \& } \\
\text { Cancer }\end{array}$ & 2015 & EUA/Inglês & $\begin{array}{l}0 \text { desenvolvimento de um padrão psicossocial de } \\
\text { cuidados paliativos em oncologia pediátrica }\end{array}$ \\
\hline PubMed & $\begin{array}{l}\text { Quality of care and relationships as } \\
\text { reported by children with cancer and their } \\
\text { parents }\end{array}$ & $\begin{array}{l}\text { Annals of Palliative } \\
\text { Medicine }\end{array}$ & 2015 & $\begin{array}{l}\text { Líbano/ } \\
\text { Inglês }\end{array}$ & $\begin{array}{l}\text { A qualidade dos cuidados paliativos prestados a } \\
\text { crianças, adolescentes e suas famílias em um Centro } \\
\text { de Câncer Infantil }\end{array}$ \\
\hline SciELO & $\begin{array}{l}\text { Cuidados paliativos em oncologia } \\
\text { pediátrica na percepção dos acadêmicos } \\
\text { de enfermagem }\end{array}$ & $\begin{array}{l}\text { Escola Anna Nery } \\
\text { Revista de Enfermagem }\end{array}$ & 2016 & $\begin{array}{l}\text { Brasil/ } \\
\text { Português }\end{array}$ & $\begin{array}{l}\text { A percepção de acadêmicos de enfermagem sobre } \\
\text { cuidados paliativos em oncologia pediátrica }\end{array}$ \\
\hline SciELO & $\begin{array}{l}\text { Cuidados paliativos em oncologia } \\
\text { pediátrica na formação do enfermeiro }\end{array}$ & $\begin{array}{l}\text { Revista Gaúcha de } \\
\text { Enfermagem }\end{array}$ & 2017 & $\begin{array}{l}\text { Brasil/ } \\
\text { Português }\end{array}$ & $\begin{array}{l}\text { A formação do acadêmico em enfermagem na área } \\
\text { dos cuidados paliativos em oncologia pediátrica }\end{array}$ \\
\hline SciELO & $\begin{array}{l}\text { Trabalhadores de enfermagem em } \\
\text { oncologia pediátrica: o uso de estratégias } \\
\text { defensivas no trabalho }\end{array}$ & $\begin{array}{l}\text { Escola Anna Nery } \\
\text { Revista de Enfermagem }\end{array}$ & 2017 & $\begin{array}{l}\text { Brasil/ } \\
\text { Português }\end{array}$ & $\begin{array}{l}\text { A percepção do profissional de enfermagem } \\
\text { em relação ao cuidado da criança com doença } \\
\text { oncológica }\end{array}$ \\
\hline SciELO & $\begin{array}{l}\text { Apoyo en duelo y burnout en equipos de } \\
\text { enfermería de unidades pediátricas de } \\
\text { hospitales chilenos }\end{array}$ & $\begin{array}{l}\text { Revista da Escola de } \\
\text { Enfermagem da USP }\end{array}$ & 2017 & $\begin{array}{l}\text { Chile/ } \\
\text { Espanhol }\end{array}$ & $\begin{array}{l}\text { A relação entre a prática profissional e o risco } \\
\text { para desenvolvimento da síndrome de Burnout em } \\
\text { profissionais de enfermagem que atuam na área de } \\
\text { oncologia pediátrica }\end{array}$ \\
\hline PubMed & $\begin{array}{l}\text { Patient's and parent's needs, attitudes, } \\
\text { and perceptions about early palliative care } \\
\text { integration in pediatric oncology }\end{array}$ & JAMA Oncology & 2017 & EUA/Inglês & $\begin{array}{l}\text { Percepção dos pacientes e dos pais a respeito } \\
\text { da integração precoce dos cuidados paliativos no } \\
\text { tratamento da criança com câncer }\end{array}$ \\
\hline
\end{tabular}


Quadro 2. Intervenções de enfermagem para a criança com câncer em cuidados paliativos

\begin{tabular}{|c|c|c|}
\hline Temas & Intervenções de Enfermagem & Resultados Esperados \\
\hline $\begin{array}{l}\text { Integração precoce } \\
\text { dos cuidados } \\
\text { paliativos }\end{array}$ & $\begin{array}{l}\text { - Introduzir os cuidados paliativos no momento do diagnóstico ou no } \\
\text { primeiro mês, concomitantemente ao tratamento curativo. } \\
\text { - Educar as famílias por meio de discussões, leituras de textos e } \\
\text { outros recursos. }\end{array}$ & $\begin{array}{l}\text { - Preparar a família para as experiências que poderão vivenciar ao longo } \\
\text { do tratamento e para lidar com o processo de morrer da criança. } \\
\text { - Amenizar os primeiros sintomas sofridos pela criança no início do } \\
\text { tratamento. }\end{array}$ \\
\hline Alívio da dor & $\begin{array}{l}\text { - Avaliar a presença e a intensidade da dor por meio de entrevista, } \\
\text { escala de dor e aspectos comportamentais. } \\
\text { - Administrar analgésicos, conforme prescrição médica. } \\
\text { - Utilizar medidas não farmacológicas: toque terapêutico, aplicação } \\
\text { de compressas quentes e frias, ludoterapia, aromaterapia. }\end{array}$ & - Redução do sofrimento e promoção de conforto. \\
\hline $\begin{array}{l}\text { Comunicação, } \\
\text { vínculo e apoio }\end{array}$ & $\begin{array}{l}\text { - Estabelecer relacionamento terapêutico por meio de comunicação } \\
\text { verbal e não verbal. } \\
\text { - Identificar sintomas psicológicos na criança utilizando escalas de } \\
\text { ansiedade e de qualidade de vida. } \\
\text { - Fornecer suporte psicossocial e espiritual à criança e ao } \\
\text { adolescente. }\end{array}$ & $\begin{array}{l}\text { - Criar e fortalecer vínculo de confiança e de afeto com a criança e a } \\
\text { família. } \\
\text { - Reduzir a angústia do paciente e proteger sua dignidade. } \\
\text { - Facilitar a adesão ao tratamento. }\end{array}$ \\
\hline 0 brincar & $\begin{array}{l}\text { - Promover atividades de recreação e aprendizagem: escola } \\
\text { hospitalar, desenho, pintura, música, brinquedo, teatro, contar } \\
\text { histórias. } \\
\text { - Fazer uso da brinquedoterapia. }\end{array}$ & $\begin{array}{l}\text { - Promover o desenvolvimento saudável e o bem-estar da criança. } \\
\text { - Reduzir o estresse e o medo durante procedimentos. }\end{array}$ \\
\hline $\begin{array}{l}\text { Cuidados com a } \\
\text { família }\end{array}$ & $\begin{array}{l}\text { - Identificar as fases do luto pelas quais a família passa. } \\
\text { - Fornecer apoio psicossocial e espiritual à família. } \\
\text { - Oportunizar o maior contato possível da criança com a família. } \\
\text { - Identificar riscos sociais da família. }\end{array}$ & $\begin{array}{l}\text { - Reduzir o sofrimento da família no processo de morte da criança. } \\
\text { - Minimizar ou solucionar problemas sociais da família. }\end{array}$ \\
\hline $\begin{array}{l}\text { Cuidados com a } \\
\text { equipe }\end{array}$ & $\begin{array}{l}\text { - Promover espaços para os profissionais falarem sobre seus } \\
\text { sentimentos. } \\
\text { - Implementar estratégias de educação permanente em cuidados } \\
\text { paliativos. } \\
\text { - Possibilitar que os profissionais vivenciem rituais de luto dentro ou } \\
\text { fora do ambiente hospitalar. } \\
\text { - Incluir a temática de cuidados paliativos em oncologia pediátrica } \\
\text { em cursos e outras oportunidades de aprendizagem. }\end{array}$ & $\begin{array}{l}\text { - Reduzir o estresse e o sofrimento da equipe. } \\
\text { - Capacitar os profissionais para os cuidados paliativos em pediatria. } \\
\text { - Contribuir para que os profissionais lidem com o luto de maneira } \\
\text { saudável. } \\
\text { - Preparar tecnicamente o enfermeiro em formação e aumentar sua } \\
\text { segurança. }\end{array}$ \\
\hline $\begin{array}{l}\text { Limitação de } \\
\text { intervenções }\end{array}$ & $\begin{array}{l}\text { - Discutir, com outros profissionais, a família e a criança, sobre } \\
\text { a limitação de procedimentos invasivos como quimioterapia e } \\
\text { ressuscitação cardiopulmonar. }\end{array}$ & $\begin{array}{l}\text { - Evitar procedimentos invasivos desnecessários, que causam desconforto } \\
\text { e não contribuem para o controle da doença. } \\
\text { - Promover qualidade de vida nos estágios finais da doença. }\end{array}$ \\
\hline $\begin{array}{l}\text { Cuidados durante e } \\
\text { após a morte }\end{array}$ & $\begin{array}{l}\text { - Permitir que a criança esteja acompanhada de seus entes } \\
\text { queridos no momento do óbito. } \\
\text { - Oportunizar que a criança morra em seu domicílio. } \\
\text { - Zelar pela estética no preparo do corpo (dar banho, trocar a roupa, } \\
\text { colocar acessórios). } \\
\text { - Realizar visita domiciliar à família após o óbito. }\end{array}$ & $\begin{array}{l}\text { - Promover uma morte digna para a criança e sua família. } \\
\text { - Tornar a experiência o menos traumática possível para a família. } \\
\text { - Demonstrar respeito à criança e à família. }\end{array}$ \\
\hline
\end{tabular}

\section{Discussão}

De acordo com os autores envolvidos, podemos definir cuidados paliativos no âmbito do câncer infantil como um atendimento integral, voltado ao paciente fora de possibilidades terapêuticas, que transcende o modelo biomédico e apresenta como objetivo aumentar a qualidade de vida da criança e de sua família, por meio de ações como: identificar precocemente sintomas biopsicossociais e espirituais, prevenir e aliviar a dor, promover conforto e apoio, incluir a criança e a família na tomada de decisões, permitir que a criança viva o mais ativamente possível em uma rotina que se assemelhe com sua vida antes da internação, viabilizar o contato com os entes queridos, entre outras. ${ }^{(9-11)}$
Cuidados paliativos e curativos são complementares, e não excludentes. Todo paciente fora de possibilidades de cura necessita de cuidados paliativos, mas nem todo paciente que está em cuidados paliativos está próximo do fim da vida. Destarte, a criança necessita de um cuidado que seja centrado na qualidade de vida e de morte, e não unicamente no momento do óbito. ${ }^{(12,13)}$ Esse cuidado deve ter como intuito evitar o aumento do sofrimento da criança e da família, e não prolongar nem adiar a morte. Quando uma criança entra em cuidados paliativos, o enfoque da assistência deixa de ser curativo e passa a ser mais realista com as condições da criança e da família. . $^{(7,13,14)}$

Após a leitura e a análise dos estudos, foram extraídas as unidades temáticas mais relevantes en- 
contradas, separadas nas seguintes categorias: "Integração precoce dos cuidados paliativos", "Alívio da dor", "Comunicação, vínculo e apoio", "O brincar", "Cuidados com a família", "Cuidados com a equipe", "Limitação de intervenções" e "Cuidados durante e após a morte". As categorias referentes às possibilidades de intervenções de enfermagem foram sintetizadas no quadro 2, com o intuito de nortear o profissional de enfermagem que atua na área da oncologia pediátrica na prestação de cuidados paliativos com embasamento científico.

\section{Integração precoce dos cuidados paliativos}

É recomendado que o cuidado paliativo em pediatria seja integrado o mais precocemente possível em casos de doenças que ameaçam a vida, como o câncer, com início preferencialmente no momento do diagnóstico ou no primeiro mês. ${ }^{(9)}$

Esse novo modelo de cuidado apresenta pontos negativos, expressados pela equipe médica, destacando-se a preocupação em gerar sobrecarga de informações e ansiedade adicional aos pais no momento do diagnóstico. Contudo, profissionais não médicos como enfermeiros e assistentes sociais acreditam que tais sentimentos são ainda maiores quando os cuidados paliativos são introduzidos tardiamente, durante a progressão ou agravamento da doença. ${ }^{(15)}$ Ainda que as informações a respeito do diagnóstico e suas implicações possam gerar tristeza e sofrimento no momento em que são transmitidas, posteriormente contribuem para a redução da ansiedade decorrente dos sintomas e efeitos do tratamento, promovendo alívio e sentimentos de esperança. ${ }^{(16)}$ É muito forte e presente em nossa cultura a associação entre cuidados paliativos e cuidados no fim da vida. O profissional de saúde deve desmistificar esse e outros mitos, construindo com a família um novo significado para cuidado paliativo que se aproxime mais do conceito de qualidade de vida.

Os pacientes que mais se beneficiariam com a integração precoce seriam aqueles com menos de $40 \%-50 \%$ de chance de cura, pois basear-se somente no prognóstico poderia excluir outras crianças e famílias com dificuldades em lidar com o diagnóstico. ${ }^{(15)}$ Esse atendimento teria como objetivo - além de oferecer apoio - educar as famílias quanto ao diagnóstico, prognóstico e outras informações referentes à doença e ao tratamento, por meio de discussões, leituras de textos e outros recursos educativos, deixando os pais mais familiarizados com determinados conceitos e preparados para vivenciar esse momento..$^{(15)}$

Levando em consideração que, desde o primeiro mês de tratamento, a criança pode vir a vivenciar sintomas como náusea, perda de apetite, ansiedade, constipação, depressão e diarreia, e que nesse primeiro momento a família e a equipe podem estar mais focadas na cura da doença do que na qualidade de vida do paciente, a introdução precoce dos cuidados paliativos poderia ser benéfica nesse período como uma terapia complementar que não exclui o tratamento curativo, mas que contempla a criança e sua família de maneira integral, minimizando os primeiros sintomas, reduzindo o sofrimento da criança e aumentando sua qualidade de vida. ${ }^{(17)}$

\section{Alívio da dor}

A dor vivenciada pela criança com câncer não é apenas uma dor física relacionada à patologia, existe uma dor mais complexa, denominada dor total, que engloba aspectos físicos, mentais e espirituais, reflexos da situação em que a criança se encontra, sendo necessária uma abordagem multiprofissional para que seu manejo seja eficaz. ${ }^{(12,18)}$ Essa abordagem deve visar à redução do sofrimento, à promoção de conforto e ao fortalecimento da criança, o que proporciona uma assistência humanizada sob uma perspectiva holística. ${ }^{(7,14)}$

O método para avaliar a dor deve ser escolhido de acordo com o desenvolvimento da criança; para aquelas que já verbalizam e são capazes de autorrelatar a dor, a entrevista deve ser considerada o padrão-ouro, e quando a criança não consegue verbalizar, o enfermeiro poderá utilizar outros instrumentos, como escalas de dor para avaliar sua intensidade e monitorar a progressão do tratamento e a efetividade das medidas de controle. ${ }^{(9,18)} \mathrm{O}$ profissional deve levar em consideração também aspectos comportamentais que indicam a presença de dor, como a posição do corpo, expressão facial, choro, frequência cardíaca, frequência respiratória e sudorese. ${ }^{(9,18)}$

O controle e o alívio da dor são um direito humano básico e devem ser realizados por meio de medidas farmacológicas, com o uso de analgésicos opioides, e 
de medidas não farmacológias, consideradas parte de um manejo integral da dor, trazendo efeitos sinérgicos ao tratamento medicamentoso. ${ }^{(9)}$ Como exemplos de medidas não farmacológicas, podem-se citar: contato físico, toque terapêutico, apoio psicológico, interação social, aplicação de compressas quentes e frias, ludoterapia, aromaterapia, entre outras. ${ }^{(10,18)} \mathrm{A}$ aplicação de intervenções não farmacológicas, como massagem, musicoterapia, exercício físico e brinquedo terapêutico instrucional, também apresenta bons resultados e comprovada eficácia no controle da dor, ansiedade e fadiga, contribuindo, do mesmo modo, para a integralidade do cuidado paliativo. ${ }^{(19)}$

\section{Comunicação, vínculo e apoio}

A comunicação entre o profissional de enfermagem, a criança com câncer e sua família vai além das palavras e do conteúdo, ela envolve meios verbais e não verbais. Uma criança que não é capaz de se comunicar por meio do diálogo, estabelecerá uma comunicação mediante mudanças em seu comportamento, sorrindo ou chorando, devendo o enfermeiro estar atento a tais sinais para conseguir suprir as necessidades da criança. A comunicação pode ocorrer por diversos modos: presença legítima e compassiva do profissional, escuta qualificada, olhares, gestos, demonstração de afeto e palavras. A comunicação terapêutica é um fator facilitador para a criação de um vínculo entre o profissional, o paciente e sua família. ${ }^{(14,20,21)}$ As relações terapêuticas estabelecidas, por sua vez, são capazes de minimizar a angústia do paciente e de proteger sua dignidade e seus valores, e facilitam a adesão ao tratamento, que passa a ser mais eficaz e menos doloroso tanto para a família quanto para a criança. $(7,14,20)$

As crianças com câncer em cuidados paliativos podem vir a apresentar sintomas psicológicos como depressão, ansiedade, angústia, tristeza, medo de ficar sozinhas e distúrbios do sono, que frequentemente não são tratados pela equipe médica. ${ }^{(9,22)}$ Entre os efeitos do tratamento, a perda de cabelo pode ser considerada uma das maiores preocupações da criança, que pode vir a se tornar vítima de brincadeiras e piadas entre seus pares. Além disso, as mudanças na rotina também podem repercutir de maneira negativa na autoimagem do paciente, uma vez que ele passa a ser privado de atividades rotineiras e brincadeiras consi- deradas normais para as outras crianças. ${ }^{(16)}$ É importante que o enfermeiro saiba identificar sintomas psicológicos na criança, utilizando estratégias como, por exemplo, escalas que avaliem o nível de ansiedade e a qualidade de vida, com o intuito de intervir precocemente, por meio de medidas não farmacológicas, para evitar agravos e minimizar o sofrimento da criança.

Ao fornecer suporte psicossocial à criança, o enfermeiro deve promover esperança, sem mentir sobre sua condição médica, e conversar sobre outros temas além daqueles relacionados à doença, o que ajuda a criança a "escapar" da sua condição atual e a não pensar no câncer. ${ }^{(13)}$ É importante que o profissional não omita informações das crianças, mas sim esclareça todas suas dúvidas por meio de uma linguagem apropriada para a faixa etária, fazendo uso de meios lúdicos (jogos, livros, vídeos, figuras e metáforas). Dessa forma, a criança será capaz de se preparar para as mudanças que seu corpo enfrentará e os procedimentos aos quais será submetida, passando a exercer certo controle sobre a situação em que se encontra e sobre seus sentimentos. ${ }^{(16)}$

A espiritualidade também deve ser considerada ao se implementar um cuidado integral; em nossa cultura, essa necessidade pode ser suprida com o contato com líderes religiosos. ${ }^{(23)} \mathrm{O}$ enfermeiro também deve atentar para as necessidades especiais dos adolescentes com câncer, para evitar que esse grupo sinta-se excluído ou negligenciado pela equipe, passando com esse paciente tanto tempo quanto passa com as crianças. ${ }^{(23)}$

\section{O brincar}

A criança tem o direito de viver, crescer, aprender e se desenvolver dentro do ambiente hospitalar, devendo sentir-se livre para brincar e aproveitar cada momento de sua vida e participar de atividades de recreação e da escola hospitalar, mesmo estando em estágio terminal. O brincar é um fator relevante para que a criança tenha uma boa morte, por meio de atividades como desenho, pintura, música, brinquedo, teatro, contar histórias, entre outras, que promovem bem-estar, conforto e alegria, e fortalecem o vínculo enfermeiro-paciente. .13,14) $^{(13)}$

A importância do brincar se dá também pelo fato de que sua prática facilita a interação enfermeiro-paciente e ajuda no alívio da tensão antes de procedimentos, propiciando a humanização do cuidado. 
Entretanto, existem limitações relacionadas a esse tipo de atividade, como restrições físicas e falta de vontade de brincar do paciente e resistência do profissional por não considerar o brincar relevante ou por falta de tempo para praticá-lo. ${ }^{(24)}$

A brinquedoterapia é uma estratégia que pode ser utilizada pelo enfermeiro que trabalha em oncologia pediátrica, pois é por meio da brincadeira que a criança expressa seus sentimentos, ansiedades e frustrações, portanto pode reduzir o estresse e o medo durante procedimentos invasivos, contribuir para a melhora de angústias psicológicas e sintomas clínicos e facilitar a adesão ao tratamento. ${ }^{(13,18)}$

\section{Cuidados com a família}

Sabe-se que, no cuidado em pediatria, criança e família são indissociáveis. ${ }^{(10,12)} \mathrm{A}$ possibilidade de um filho ir a óbito é descrita na literatura como uma das vivências mais terríveis e devastadoras para os pais e pode desestruturar o funcionamento familiar, principalmente por ser considerada antinatural. ${ }^{(13)}$ Sendo assim, a equipe de enfermagem deve ser capaz de reconhecer as diferentes fases do luto pelas quais a família passa, para construir estratégias de enfrentamento adequadas. ${ }^{(12)}$ Os pais muitas vezes não estão preparados para receber determinadas notícias ou para responder a questionamentos da criança, portanto é importante que a equipe estabeleça uma relação sincera com a família e que os pais sejam preparados para responder a todas as perguntas dos filhos, pois todo tipo de conspiração silenciosa, mentiras ou evasivas pode ser prejudicial ao vínculo de confiança entre profissional-família ou família-paciente. ${ }^{(13,21)}$

O profissional de enfermagem deve apoiar, transmitir segurança e tranquilizar pais e irmãos, orientar e incluir a família nos cuidados da criança, além de oportunizar o maior contato possível da criança com pessoas próximas (pais, irmãos, avós), por meio da possibilidade de mais visitas, pois não é possível que a criança tenha uma morte digna sem a participação da família durante todo o processo. ${ }^{(7,13,21)}$ O enfermeiro deve estar atento às necessidades sociais da família; durante o adoecimento da criança com câncer, os pais podem apresentar problemas financeiros, relacionados a perda de emprego, a dificuldades para cuidar de outros filhos no domicílio ou mesmo ao tratamento da criança, considerando as restrições relacionadas aos planos de saúde, no caso do sistema privado. ${ }^{(23)}$

Esses achados coincidem e são respaldados pelo conceito de cuidados paliativos em pediatria proposto pela Organização Mundial da Saúde (OMS), que valoriza o cuidado à família, tal como a inserção dessa enquanto parte de uma abordagem multidisciplinar que contribui para a efetividade e o sucesso da assistência paliativa. ${ }^{(5)}$

\section{Cuidados com a equipe}

Grande parte dos estudos analisados mostra que o processo de cuidar da criança com câncer é um gerador de sobrecarga de trabalho e sofrimento para toda a equipe de enfermagem. Quanto maior o vínculo entre o profissional e a criança, maior o sofrimento no momento da perda. Dessa forma, muitos profissionais tendem a "não se apegar" à criança, executando um cuidado distante, silencioso e mecânico. Entre outras estratégias relatadas pelos profissionais para reduzir o sofrimento, está separar o "lado pessoal" do "lado profissional" e se esquecer dos pacientes após o término da jornada de trabalho, além dos refúgios em momentos de lazer. ${ }^{(9)}$ Tais estratégias são importantes, pois protegem a saúde mental do profissional e amenizam seu sofrimento momentaneamente, porém, quando são utilizadas em excesso, podem alienar o profissional e até levá-lo ao adoecimento psíquico. ${ }^{(25)}$ Dados similares também foram identificados em outras pesquisas, atentando para o uso recorrente e inflexível dos mecanismos de defesa como possível gerador de sofrimento psíquico e adoecimento ao profissional. ${ }^{(26)}$ Por outro lado, foi visto que a construção de um vínculo afetivo, assim como ações de demonstração de amor, carinho e apego, promove a qualidade de vida da criança e o reconhecimento e a gratidão da família, e faz com que o profissional de enfermagem tenha uma percepção positiva de seu próprio trabalho e sinta-se bem consigo mesmo. ${ }^{(10,20)}$

Em um estudo realizado com 153 profissionais de enfermagem que trabalhavam em unidades de terapia intensiva pediátricas e unidades oncológicas em hospitais chilenos, constatou-se que $89 \%$ deles apresentavam risco de desenvolver síndrome de Burnout e $4 \%$ já haviam desenvolvido, por causa de altos níveis de cansaço emocional e baixos níveis de realização pessoal. ${ }^{(27)}$ 
Os profissionais de enfermagem necessitam de capacitação e suporte psicológico especializado para lidar com as perdas de seus pacientes; espaços para eles poderem falar abertamente sobre seus sentimentos no serviço seriam capazes de transformar o sofrimento em momentos de prazer e até mesmo de gerar estratégias potentes capazes de modificar seu cotidiano de trabalho..$^{(7,18,21,25,27)}$ De acordo com os profissionais, entre as estratégias que seriam benéficas para a redução do sofrimento no ambiente de trabalho, foram citadas: suporte psicológico e psicoterapia; capacitações sobre como lidar com a morte e como fornecer cuidados paliativos; espaços para troca de experiências entre os profissionais; prática de esportes; fé e religião. ${ }^{(26,28)}$

É necessário também que o serviço favoreça o desenvolvimento de rituais de luto dentro da unidade e que possibilite a participação dos profissionais nos rituais funerários das crianças, se assim desejarem. ${ }^{(27)}$

$O$ profissional também refere não ter embasamento teórico para saber lidar com a morte na infância, sendo muitas vezes orientado por profissionais que já trabalham na área há mais tempo, em como conduzir esse tipo de cuidado, tendo como base suas experiências próprias. Acadêmicos de enfermagem não se sentem seguros e preparados para cuidar de uma criança com doença oncológica sem possibilidade de cura, em razão da ausência de contato ou da abordagem superficial dessa temática ao longo do curso. ${ }^{(29)}$ Resultados semelhantes foram encontrados em outros estudos, apontando falhas na formação acadêmica dos enfermeiros para a promoção dos cuidados paliativos. O despreparo técnico e emocional desses profissionais para o lidar com a criança com câncer em cuidados paliativos pode estar relacionado à superficialidade com que esse tema é tratado nas instituições de ensino. ${ }^{(19)}$

É necessário que a temática de cuidados paliativos seja incluída em ações de educação permanente destinadas aos profissionais que já atuam na área, mas também nos currículos dos cursos de graduação em Enfermagem, por meio de disciplinas optativas e obrigatórias e também de cursos de capacitação, e o contato com esse tema deve ser processual e transversal, visando a uma progressiva aquisição de conhecimento, por meio de estratégias de sensibilização dos graduandos, como dinâmicas grupais. ${ }^{(21,29)}$

\section{Limitação de intervenções}

Partindo do princípio de que em cuidados paliativos não se deve reduzir nem prolongar o tempo de vida da criança, a equipe multiprofissional deve considerar a opção de limitar terapias invasivas desnecessárias que causam desconforto e não contribuirão para o controle da doença. ${ }^{(9,13,23)}$ Dentre essas intervenções, pode-se destacar a quimioterapia curativa ou paliativa e a ressuscitação cardiopulmonar. O prolongamento do tratamento quimioterápico, por exemplo, pode fazer com que a criança sem chances de cura apresente um número maior de sintomas desagradáveis no final de sua vida. (13) É de extrema importância que o profissional especifique em seu registro o que se pode e o que não se pode fazer, evitando o uso de termos vagos que dependam da interpretação subjetiva de cada profissional. ${ }^{(13)}$

A decisão de limitar ou não as intervenções deve ser tomada pela equipe multiprofissional em conjunto com a família e com a criança. Contudo, o enfermeiro muitas vezes se sente inseguro para interromper o tratamento, pois nem sempre é capaz de aceitar a morte da criança, negando a proximidade com ela e prolongando o processo de morrer. ${ }^{(7)}$

Raramente se vê a criança sendo incluída na tomada de decisões. Um estudo realizado em uma unidade de oncologia pediátrica dos EUA mostrou que a maioria das crianças apresentava insatisfação quanto a participarem da tomada de decisões. ${ }^{(2)}$ Por outro lado, os adolescentes mostraram menor descontentamento nesse sentido, pois, pelo desenvolvimento cognitivo e capacidade de tomar decisões mais sábias, acabam sendo mais ativos em seu tratamento do que as crianças menores. ${ }^{(23)}$

\section{Cuidados durante e após a morte}

Em cuidados paliativos, o profissional deve zelar para que a criança tenha uma "boa morte", ou seja, com o mínimo de sofrimento possível, acompanhada pelos seus entes queridos e no local de preferência da criança e/ou de sua família. ${ }^{(9,13)}$

Na maioria dos casos, o melhor local para a criança morrer é seu domicílio, ao lado de sua família. Portanto, dependendo do estado clínico da criança, a opção de alta deve ser oferecida à família e à criança e discutida com a equipe multiprofissional. ${ }^{(9,13)}$ Caso a criança tenha alta, o enfermeiro deverá educar e apoiar os familiares, 
incentivando-os a realizarem os cuidados, os quais deverão ter continuidade no domicílio. Quando possível, o serviço deverá disponibilizar uma equipe de home care para dar seguimento ao cuidado no domicílio.(9)

$\mathrm{O}$ cuidado humanizado transcende o momento do óbito. Após a morte do paciente, o profissional de enfermagem ainda pode implementar cuidados na tentativa de tornar esse momento o menos traumático possível. ${ }^{(9)} \mathrm{O}$ corpo da criança possui grande valor sentimental para a família, pois simboliza o que aquele ser representou durante sua trajetória. A equipe de enfermagem pode realizar medidas como colocar o paciente no caixão para que a mãe não presencie esse processo, que pode ser uma das grandes aflições dos familiares. Cuidados com a estética no preparo do corpo, como dar banho, trocar a roupa e colocar acessórios, além de uma visita domiciliar à família após o óbito, demonstram preocupação e respeito para com a criança e sua família. ${ }^{(9)}$

Mesmo após o óbito da criança, os pais podem permanecer com dúvidas a respeito do tratamento, as quais, se não forem trabalhadas, podem causar sentimentos de arrependimento, mágoa e angústia. Sendo assim, é necessário que os pais tenham a certeza de que todo o melhor foi proporcionado à criança. Por meio do vínculo e do relacionamento com a família e com a criança, a equipe de enfermagem é capaz de ressignificar a experiência dos pais sobre a hospitalização, contribuindo para o processo de elaboração do luto e prevenção de complicações relacionadas ao seu enfrentamento. ${ }^{(30)}$

\section{Conclusão}

Dessa forma, pode-se dizer que os cuidados paliativos trazem inúmeros benefícios para a criança com câncer e sua família, destacando o aumento da qualidade de vida da criança e a promoção de um processo de morrer com dignidade e o mínimo de sofrimento possível para a criança e sua família. Entretanto, esse modelo de assistência só é possível se os profissionais de saúde compreenderem e praticarem um cuidado paliativo legítimo, pautado pelos princípios de humanização e de saúde holística. O enfermeiro tem papel relevante em todas as etapas dos cuidados paliativos, desde a sua introdução precoce no tratamento, sua imple- mentação - com o alívio de sintomas e promoção de conforto, construção de vínculo afetivo e de confiança, apoio psicossocial e espiritual à família e à criança, suporte psicológico e capacitação da equipe de enfermagem - até o seu término - com a realização de medidas que minimizem o sofrimento da criança no momento da morte e durante o luto da família.

\section{Referências}

1. Alves CA, Deslandes SF, Mitre RM. A gestão do processo de trabalho da enfermagem em uma enfermaria pediátrica de média e alta complexidade: uma discussão sobre cogestão e humanização. Interface. 2011;15(37):351-61.

2. Brasil. Ministério da Saúde. Instituto Nacional de Câncer (INCA). Particularidades do câncer infantil [Internet]. Rio de Janeiro: Inca [citado 2016 Ag0 27]. Disponível em: http:// www.inca.gov.br/conteudo_view.asp?id=343

3. Brasil. Ministério da Saúde. Instituto Nacional de Câncer (INCA). Estimativa 2010: incidência de câncer. Rio de Janeiro: Ministério da Saúde; 2009.

4. Brasil. Ministério da Saúde. Instituto Nacional de Câncer (INCA). Diagnóstico precoce do câncer na criança e no adolescente. $2^{\text {a }}$ ed. Rio de Janeiro: Ministério da Saúde; 2011.

5. World Health Organization (WHO). Planning and implementing palliative care services: a guide for programme managers. Genève: WHO; 2016.

6. Mutti CF, Padoin SMM, Paula CC. Espacialidade do ser-profissional-de-enfermagem no mundo do cuidado a criança que tem câncer. Esc Anna Nery. 2012;16(3):493-9.

7. Souza LF, Misko MD, Silva L, Pole K, Santos MR, Bousso RS. Morte digna da criança: percepção de enfermeiros de uma unidade de oncologia. Rev Esc Enferm USP. 2013;47(1):30-7.

8. Mendes KD, Silveira RC, Galvão CM. Revisão integrativa: método de pesquisa para a incorporação de evidências na saúde e na enfermagem. Texto Contexto Enferm. 2008;17(4):758-64.

9. Valadares MT, Mota JA, Oliveira BM. Palliative care in pediatric hematological oncology patients: experience of a tertiary hospital. Rev Bras Hematol Hemoter. 2014;36(6):403-8.

10. Reis TL, Paula CC, Potrich T, Padoin SMM, Bin A, Mutti CF, Bubadué RM. Relações estabelecidas pelos profissionais de enfermagem no cuidado às crianças com doença oncológica avançada. Aquichán. 2014;14(4):496-508.

11. Ito Y, Okuyama T, Ito Y, Kamei M, Nakaguchi T, Sugano K, et al. Good death for children with cancer: a qualitative study. Jpn J Clin Oncol. 2015;45(4):349-55.

12. Silva AF, Issi HB, Motta MG. A família da criança oncológica em cuidados paliativos: 0 olhar da equipe de enfermagem. Cienc Cuid Saude. 2011;10(4):820-7.

13. Abreu MC. Enfoque interdisciplinar a la calidad de vida y de muerte en oncopediatria. Rev Cub Enferm. 2011;27(1):98-105.

14. França JR, Costa SF, Nóbrega MM, Lopes ME. Cuidados paliativos à criança com câncer. Rev Enferm UERJ. 2013;21(esp.2):779-84.

15. Dalberg T, Jacob-Files E, Carney PA, Meyrowitz J, Fromme E, Thomas G. Pediatric oncology providers perceptions of barriers and facilitators to early integration of pediatric palliative care. Pediatr Blood Cancer. 2013;60(11):1875-81.

16. Amador DD, Rodrigues LA, Mandetta MA. “É melhor contar do que esconder”: a informação como um direito da criança com câncer. Rev Soc Bras Enferm Ped. 2016;16(1):28-35.

17. Levine DR, Mandrell BN, Sykes A, Pritchard M, Gibson D, Symons HJ, et al. Patient's and parent's needs, attitudes, and perceptions about early palliative care integration in pediatric oncology. JAMA Oncol. 2017;3(9):1214-20.

18. Guimarães TM, Silva LF, Santo FH, Moraes JR. Cuidados paliativos em oncologia pediátrica na percepção dos acadêmicos de enfermagem. Esc Anna Nery. 2016;20(2):261-7.

19. Silva e Sousa ADR, Silva LF, Paiva ED. Intervenções de enfermagem nos cuidados paliativos em Oncologia Pediátrica: revisão integrative. Rev Bras Enferm. 2019;72(2):556-66.

20. França JR, Costa SF, Lopes ME, Nóbrega MM, França IS. Importância da comunicação nos cuidados paliativos em oncologia pediátrica: enfoque na Teoria Humanística de Enfermagem. Rev Latino-Am Enfermagem. 2013;21(3):1-7. 
21. Silva AF, Issi HB, Motta MG, Botene DZ. Cuidados paliativos em oncologia pediátrica: percepção, saberes e práticas na perspectiva da equipe multiprofissional. Rev Gaúcha Enferm. 2015;36(2):56-62.

22. Weaver MS, Heinze KE, Kelly KP, Wiener L, Casey RL, Bell CJ, et al. Palliative care as a standard of care in pediatric oncology. Pediatr Blood Cancer. 2015;62:829-33.

23. Al-Gharib RM, Abu-Saad Huijer H, Darwish H. Quality of care and relationships as reported by children with câncer and their parents. Ann Palliat Med. 2015;4(1):22-31.

24. Soares VA, Silva LF, Cursino EG, Goes FGB. 0 uso do brincar pela equipe de enfermagem no cuidado paliativo de crianças com câncer. Rev Gaúcha Enferm. 2014;35(3):111-6.

25. Viero V, Beck CL, Coelho AP, Pai DD, Freitas PH, Fernandes MN. Trabalhadores de enfermagem em oncologia pediátrica: 0 uso de estratégias defensivas no trabalho. Esc Anna Nery. 2017;21(4):1-8.
26. Pacheco CL, Goldim JR. Percepções da equipe interdisciplinar sobre cuidados paliativos em oncologia pediátrica. Rev Bioética. 2019;27(1):67-75.

27. Vega PV, Rodriguez RG, Galdamez NS, Molina CF, Orellana JS, Villanueva AS, et al. Apoyo en duelo y burnout en equipos de enfermería de unidades pediátricas de hospitales chilenos. Rev Esc Enferm USP. 2017;51:1-6.

28. Macedo A, Mercês NN, Silva LA, Sousa GC. Nurses' Coping Strategies in Pediatric Oncology: An Integrative Review. Rev Fund Care Online. 2019;11(3):718-24.

29. Guimarães TM, Santo LH, Moraes JR, Pacheco ST. Cuidados paliativos em oncologia pediátrica na formação do enfermeiro. Rev Gaúcha Enferm. 2017;38(1):1-9.

30. Santos MR, Wiegand DL, Sá NN, Misko MD, Szylit R. From hospitalization to grief: meanings parents assign to their relationships with pediatric oncology professional. Rev Esc Enferm USP. 2019;53:e03521. 